\title{
Influence of the Temperature on Coated Bituminous of Road Structures in Senegal (West Africa)
}

\author{
Birame Diouf $^{*}$, Adama Dione ${ }^{2}$, Papa Sanou Faye ${ }^{1}$, Khalil Cissé $^{3}$ \\ ${ }^{1}$ Mechanics and Modeling Laboratory, UFR Engineering Sciences, University of Thies, Thies, Senegal \\ ${ }^{2}$ Institute of Earth Sciences, Cheikh Anta Diop University, Dakar, Senegal \\ ${ }^{3}$ Laboratory of Materials, Mechanics and Hydraulics, Polytechnic School of Thies, Thies, Senegal \\ Email: *dbirame.am91@gmail.com
}

How to cite this paper: Diouf, B., Dione, A., Faye, P.S. and Cissé, K. (2020) Influence of the Temperature on Coated Bituminous of Road Structures in Senegal (West Africa). Open Journal of Civil Engineering, 10, 321-336.

https://doi.org/10.4236/ojce.2020.104025

Received: September 30, 2020

Accepted: December 7, 2020

Published: December 10, 2020

Copyright (c) 2020 by author(s) and Scientific Research Publishing Inc. This work is licensed under the Creative Commons Attribution International License (CC BY 4.0).

http://creativecommons.org/licenses/by/4.0/

\begin{abstract}
The Senegalese road network is strongly influenced in the long term by seasonal variations in climate and weather conditions. Indeed, much of the damage is due to these environmental factors. The objective of this paper is to study the behaviour of bituminous structures under the effect of high temperatures. Material samples were taken for a physico-mechanical characterization of the coated components. The results show that Marshall creep (2.87, $3.39,5,5.5 \mathrm{~mm}$ ) and the bitumen penetrability increase with the increasing of temperatures respectively from $34^{\circ} \mathrm{C}$ to $45^{\circ} \mathrm{C}$ and from $20^{\circ} \mathrm{C}$ to $50^{\circ} \mathrm{C}$. Marshall Stability drops from $15.81 \mathrm{kN}$ to $11.31 \mathrm{kN}$ for temperatures between $34^{\circ} \mathrm{C}$ and $45^{\circ} \mathrm{C}$. The simulation carried out on Alize-LCPC shows an increase in distortions of traction at the basis of the rolling layer and at the top of the platform if temperatures vary between $34^{\circ} \mathrm{C}$ and $45^{\circ} \mathrm{C}$. This work makes it possible to conform that the bituminous concrete is thermally sensitive and the hypothesis of fixing the constant modulus of the bituminous layers in Senegal for all projects remains unsuitable for a good dimensioning of sustainable road structures. The knowledge of the equivalent regional temperature will make it possible to produce quality pavements with a long lifespan.
\end{abstract}

\section{Keywords}

Asphalt Mixes, Coated, Senegal, Thermo, Susceptibility, Performance, Dimensioning

\section{Introduction}

The instability that suffers the Senegal's road structures is alarming and affects 
the comfort and safety of road users (Figure 1). The causes of these disturbances are diverse. The main problem of the short service life of road structures is due to under sizings caused by the uncontrolled use of inappropriate characteristics in stress and strain verification codes [1]. The under sizing of pavements is also due to the use of high modulus resulting in low pavement thicknesses [2]. The use of a constant rigidity modulus in all road projects justifying the absence of modulus testing often leads to premature layer degradation. The rational dimensioning with ALIZE-LCPC considers all materials used as linear elastics and characterized by their modulus of rigidity and their Poisson's ratio [3]. This constitutes a lack of precision in dimensioning, because the behavior of granular materials is non-linear elastic, whereas the behavior of bituminous materials is linear viscoelastic with low deformations. On the other hand, in Senegal, the level of formulation achieved so far for most of the country's road networks is level 0 relative to the Marshall and Duriez tests. The advent of the turnpike highway, due to its immensity and importance, is a rare exception and enriches the picture a little by adding the test of gyratory shear press for the International Airport Blaise Diagne (AIBD) project and on IlaTouba, we take into account the rutting. This is far away from coverage of the technical exigency required for a sustainable road project. In addition to this, the instructions of unsubstantiated of Ageroutein the Catalogue of New Pavement Structures and also the Pavement Sizing Guide in Senegal (2015) in which a fixed equivalent temperature of $34^{\circ} \mathrm{C}$ is specified and generalized in the whole country in an environment where average temperatures from 2007 to 2017 range from $32.3^{\circ} \mathrm{C}$ to $44.7^{\circ} \mathrm{C}$. The objective of this article is to propose a formula for BBSG and to monitor the evolution of its performances according to climatic zones.

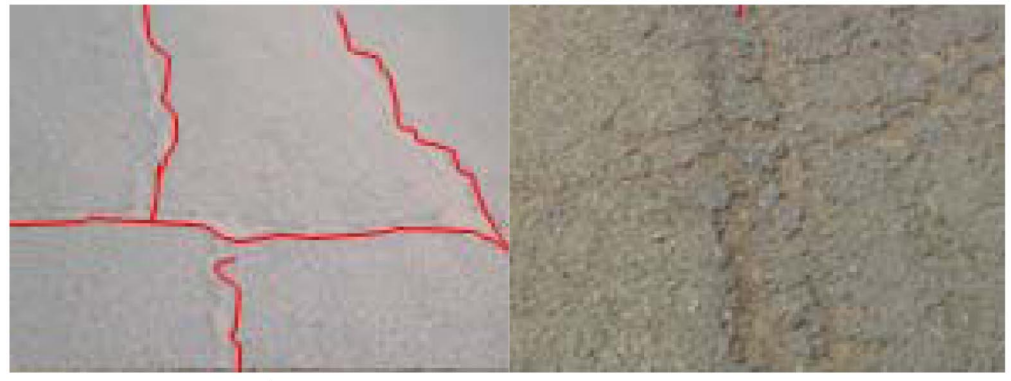

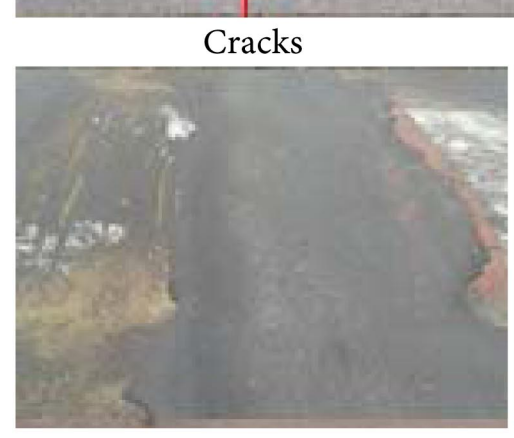

Ruttings
Extractions

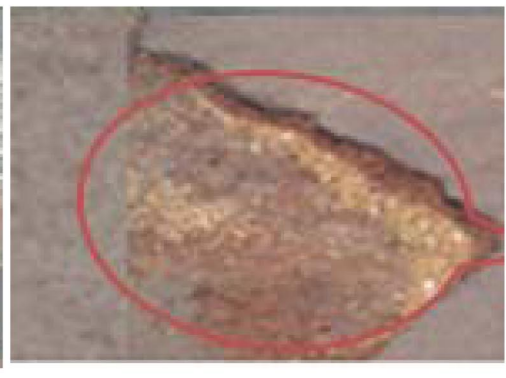

Pot-holes

Figure 1. State of road degradation in Senegal. 
This work highlights, through both experimental and analytical results, the effects of a variation in temperature. They allow us to confirm that the coated bituminous are thermally sensitive and would be related to the short life of our roads and their premature degradation.

\section{Methodology}

The results presented in this study concern samples of basalt material from the Ngoundiane quarry and bitumen supplied by the ERES plant. The basaltic granules were subjected to physical characterization by means of grading analysis, sand equivalent and flattening coefficient tests (A) on the one hand and mechanical tests through the Los Angeles test (LA) and Micro Deval test (MDE) in the presence of MDE water on the other hand. The bitumen underwent geotechnical acceptance tests through penetrability and ball and ring temperature tests to confirm the class. This physico-mechanical characterization completed with bitumen identification tests was used as the basis for a bituminous concrete formulation $0 / 14$. This will be followed by a simulation of the reaction of the materials in relation to a variation in temperature depending on the climatic zone.

Taking as a reference the Aibd-Mbour-Thies motorway project on the Somone-Mbour axis for the formulation of the semi-grained asphalt concrete (BBSG), we will extend it on the national territory using the local maximum temperature in order to see the reaction of the asphalt mix. The project is agreed on a linear of $18 \mathrm{~km}$ with the coordinates of the upstream point (280780.23; $1607118.66)$ and the downstream point $(294804.10 ; 1596310.40)$. The characteristics of the project are as follows (Table 1).

\section{Geotechnical Characterization of the Materials of Study}

\subsection{Aggregates}

The aggregates used in this study are the $0 / 3,3 / 8$ and $8 / 16$ basaltic fractions commonly used in Senegal for the manufacture of bituminous concrete for rolling layer (Figure 1). The tests carried out on the granules relate to the intrinsic

Table 1. Design data for the Aibd-Mbour-Thiès motorway project on the Somone-Mbour axe.

\begin{tabular}{ccccc}
\hline Characteristics & Surface: BBSG3 & Base: GB4 & Foundation: Gla & Platform: PF2 \\
\hline Modulus (34 $\left.{ }^{\circ} \mathrm{C}, 10 \mathrm{hz}\right) ;(\mathrm{MPa})$ & 1896 & 2386 & - & - \\
Modulus (MPa) & - & - & 1500 & 75 \\
Poisson's ratio & 0.45 & 0.36 & 0.25 & - \\
Type of traffic & & C5 & \\
Dimensioning time (years) & \multicolumn{2}{c}{20} \\
Geometric growth rate (\%) & \multicolumn{2}{c}{3} \\
Annual average daily traffic (PL) & \multicolumn{2}{c}{695} \\
\hline
\end{tabular}


characteristics giving an idea of their physical and mechanical identifications. The grain size distribution allowed us to identify the distribution of basalt grains according to the meshes and to draw the curves of each class of aggregates (Figure 2). The determination of the specific weight of the granular fractions of Gecamines basalt was carried out by hydrostatic weighing for classes $3 / 8$ and $8 / 16$ and by pycnometer measurement for class $0 / 3$ and are relative to the values recorded in Table 2. Following the completion of the g aggregates characterisation tests, a comparison is made between the results obtained and the project specifications (Table 2).

The sand equivalent test (ES) value, which is much higher than required, clearly shows the proper quality of the granules, in other words, it proves the absence of a considerable proportion of undesirable fine elements. The flattening test carried out on basalt shows a value of $14.9 \%$ for class $8 / 16$ and $15 \%$ for class $3 / 8$. These values meeting the specifications of the project confirm the rounded shape of the grains. The LA and MDE values confirm the ability of the granules to resist to impacts. The results presented in Table 2 meet the project specifications and show that gravels of a basaltic nature are well suited for a 0/14 spindle bituminous concrete formulation.

Table 2. Results of the granules identification tests.

\begin{tabular}{lccccc}
\hline & Characteristics & & Results & Specifications \\
\hline & Granular classes & $0 / 3$ & $3 / 8$ & $8 / 16$ & - \\
\hline \multirow{2}{*}{ Physical } & Specific weights & 2.98 & 2.94 & 2.95 & - \\
& Sand Equivalent, SE & - & 78.6 & - & $>40$ \\
& Flattening coefficient, A & - & 15.0 & 14.9 & $\leq 25$ \\
Mechanical & Los Angeles, LA & - & 12 & - & $\leq 20$ \\
& Micro Deval underwater, MDE & - & 20 & - & \\
\hline
\end{tabular}

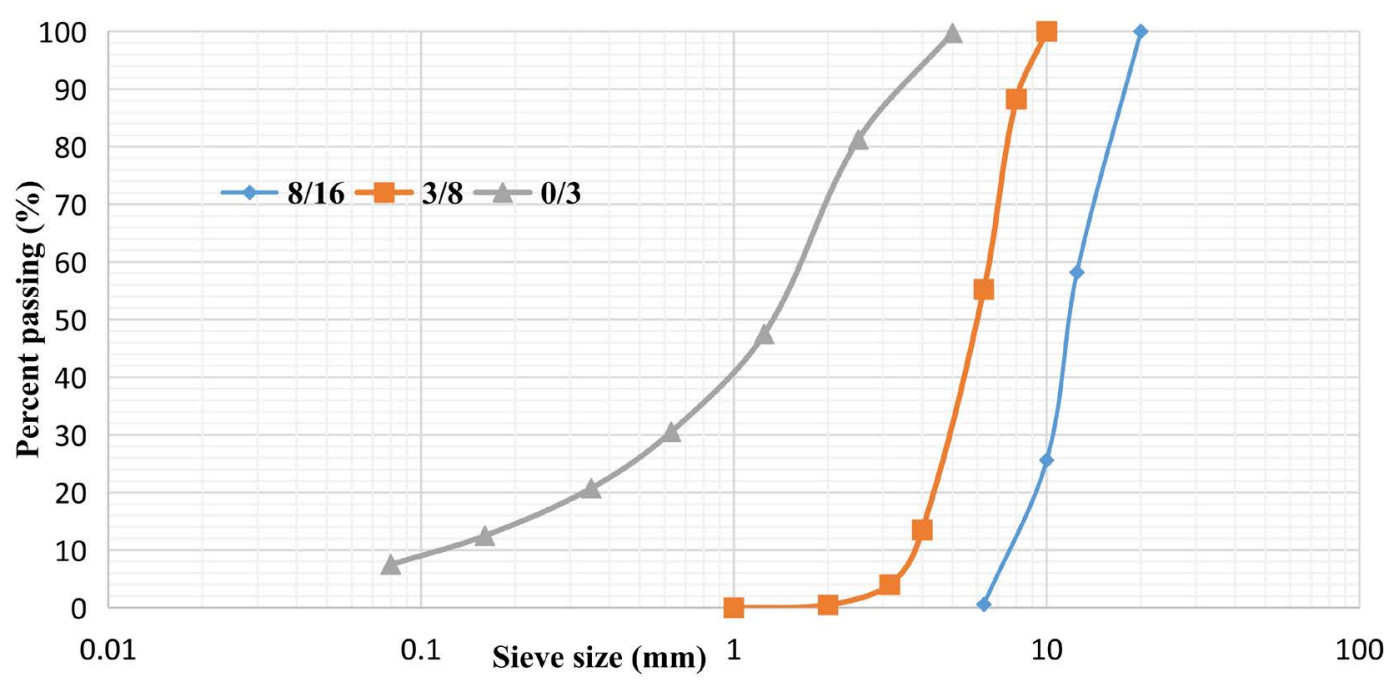

Figure 2. Particle size curves of the retained granular fractions. 


\subsection{Bitumen Identification}

The bitumen used in our work is of class 50/70. The identification made on this pure bitumen relates to the needle penetrability and the ball and ring temperature. The values found are recorded in Table 3.

The penetrability and ball and ring temperature (TBA) values obtained from laboratory tests fall within the permissible ranges and therefore confirm the bitumen class. The results presented in Table 2 and Table 3 meet the project specifications and show that gravels of a basaltic nature and 50/70 bitumens are well suited for a $0 / 14$ spindle bituminous concrete formulation.

\section{Formulation of a BBSG}

The retention of $51 \%$ of $0 / 3,18 \%$ of $3 / 8$ and $31 \%$ of $8 / 16$ resulted in a granular mixing curve that fits into the reference $0 / 14$ spindle (Figure 3 ). The Marshall method, which consists in subjecting the granular mixture to different bitumen contents starting from a minimum content equal to $5.1 \%$, allowed us to select the dosage that offers optimal Marshall characteristics (Table 4) and to draw the Marshall stability (Figure 4) and apparent volumetric mass (MVA) (Figure 5) curves depending on the binder content.

Table 3. Results of bitumen identification tests.

\begin{tabular}{cccc}
\hline Characteristics & Standards & Results & Specifications \\
\hline Penetrability $(1 / 10 \mathrm{~mm})$ & NF T 66-004 & 55.51 & $50-70$ \\
TBA $\left({ }^{\circ} \mathrm{C}\right)$ & NF T 66-008 & 49 & $45-51$ \\
\hline
\end{tabular}

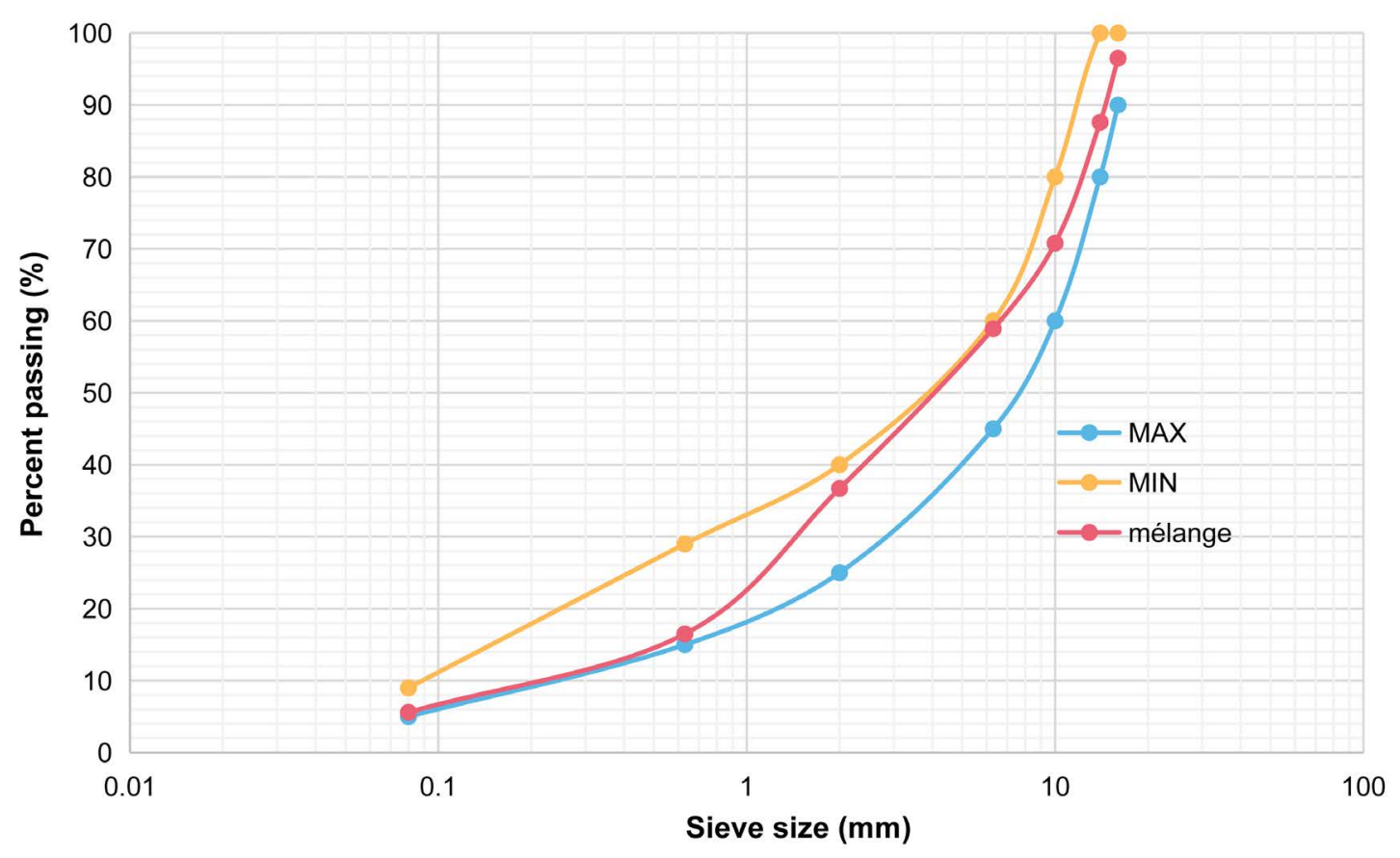

Figure 3. Particle size curve of the mixture. 
Table 4. Marshall and Duriez test results and specifications.

\begin{tabular}{cccc}
\hline & Characteristics & Values obtained & Acceptable values \\
\hline Stability $(\mathrm{daN})$ & 1320 & $>800$ \\
& Creep $(\mathrm{mm})$ & 2.9 & $<4$ \\
& Compactness (\%) & 98.38 & $>97$ \\
\hline & $\mathrm{Rc} 24 \mathrm{~h}$ à $18^{\circ} \mathrm{C}(\mathrm{MPa})$ & 8.01 & $>7$ \\
$\mathrm{Rc} 7 \mathrm{~d}$ à $18^{\circ} \mathrm{C}(\mathrm{MPa})$ & 7.16 & $>0.75$ \\
$\mathrm{Rc}$ & 0.78 & $92-96$ \\
\hline
\end{tabular}

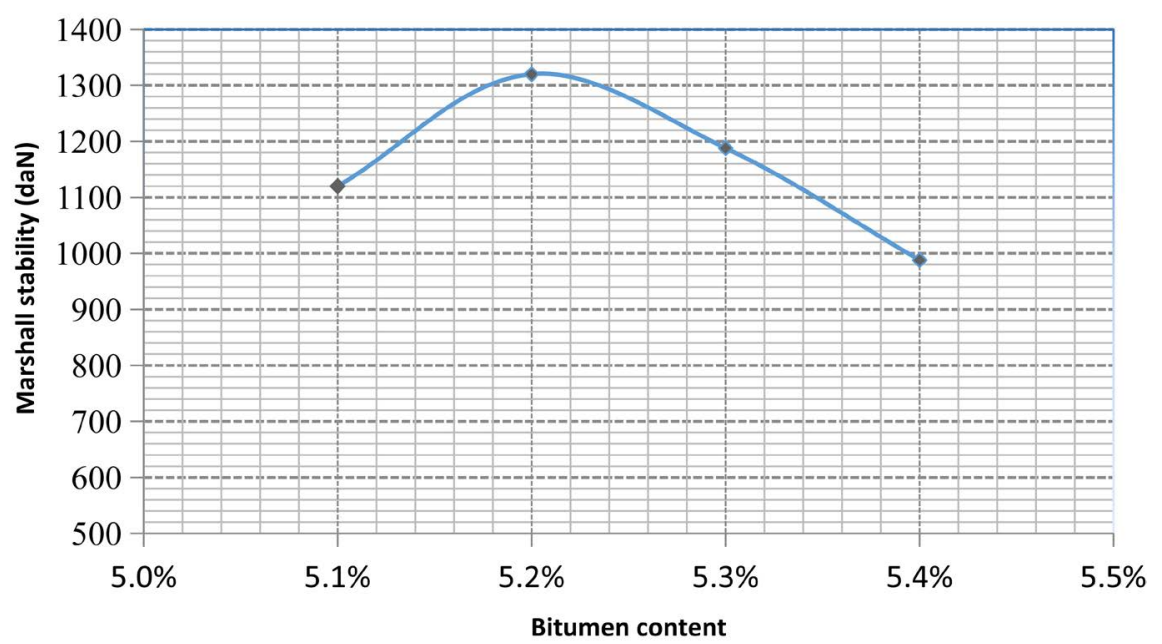

Figure 4. Marshall stability curve related to binder content.

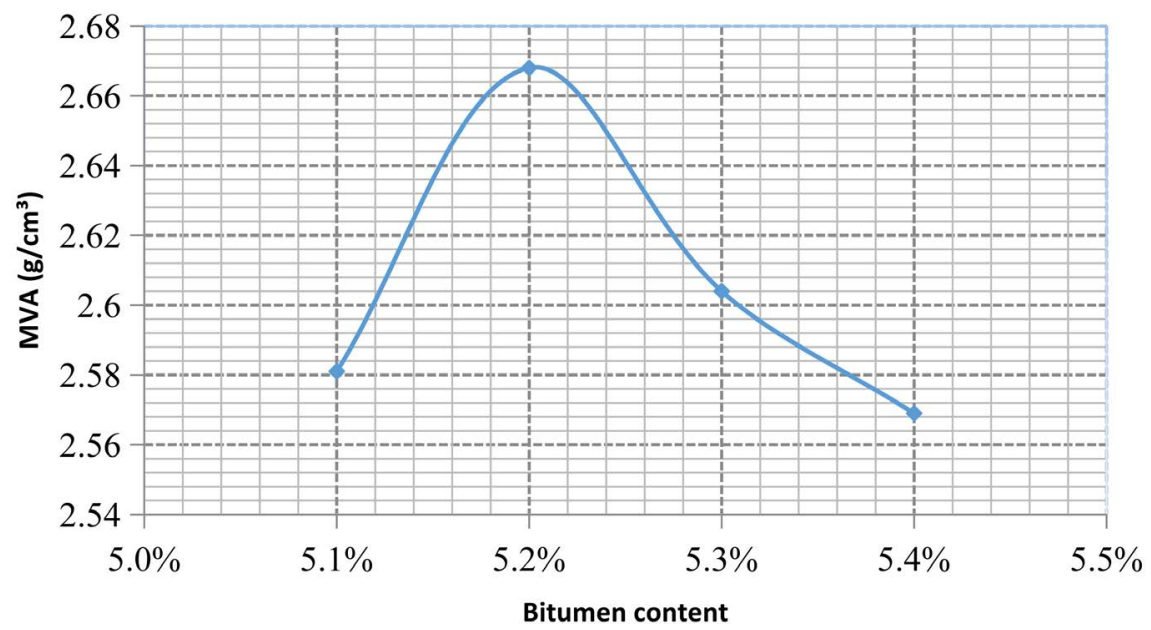

Figure 5. MVA curve related to binder content.

The curves showing the evolution of stability and the apparent density allow a bitumen content of $5.2 \%$. Then, the optimum mix will consist of:

- $51 \%$ basalt $0 / 3$; 
- $18 \%$ basalt $3 / 8$;

- $31 \%$ basalt $8 / 16$;

- $5.2 \% 50 / 70$ bitumen.

The modulus of richness will be taken equal to 3.6 and the void percentage retained for Marshall sample tubes will be of about $2 \%$. In order to confirm this binder content of $5.2 \%$, the Marshall test is completed by the Duriez test, which allows comparison with the specification values (Table 4 ). The ratio $\mathrm{R}$ 'c/Rc = 0.78 superior to 0.75 confirms the water resistance of the bituminous concrete.

Based on the experimental results, we find that the Marshall and the Duriez characteristics of the formulated $0 / 14$ bituminous concrete meet the required specifications for geotechnical design on the Aibd-Mbour-Thies highway.

\section{Thermal Sensitivity of Materials}

The study of the susceptibility of materials related to the temperature was carried out taking into account the climatic conditions of the different regions of Senegal. The exploitation of climatic data recorded by ANACIM (National Agency of Civil Aviation and Meteorology) over the period from 2007 to 2017 made it possible to draw diagrams of temperature variation (Figure 6) and insolation (Figure 7).

Figure 6 shows that the temperature dispersed throughout the territory. Its values range from $32^{\circ} \mathrm{C}$ in the Dakar region (colder) to $45^{\circ} \mathrm{C}$ in the localities of Kaffrine and Matam (warmer regions). This variation is due to a combination of cosmic, meteorological and geographical factors. Generally the maximum values

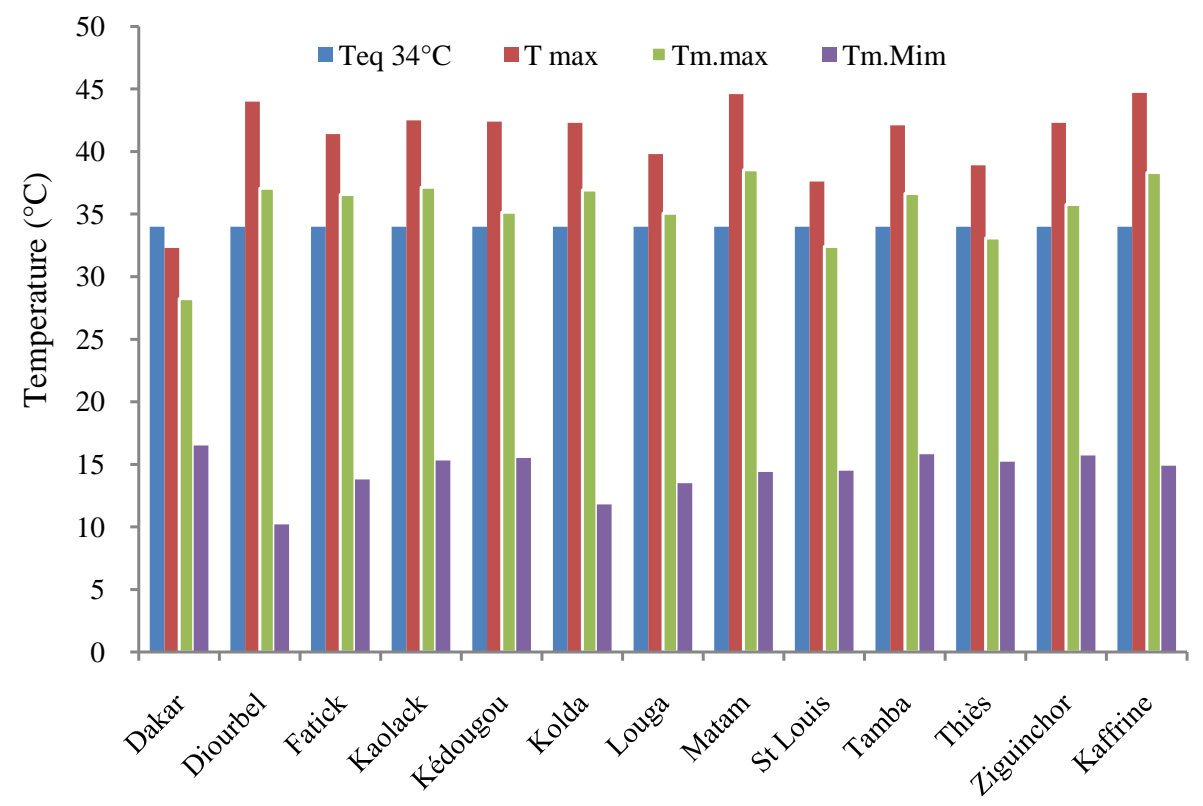

Figure 6. Graph of maximum, mean and minimum temperatures in Senegal [4]. Max = maximum $; \mathrm{m}=$ mean; $\min =$ minimum; Teq $=$ equivalent temperature; Tmax $=$ Maximum monthly average temperature; Tm.max = Average temperature 2007-2017; Tm.min = Minimum monthly average temperature. 


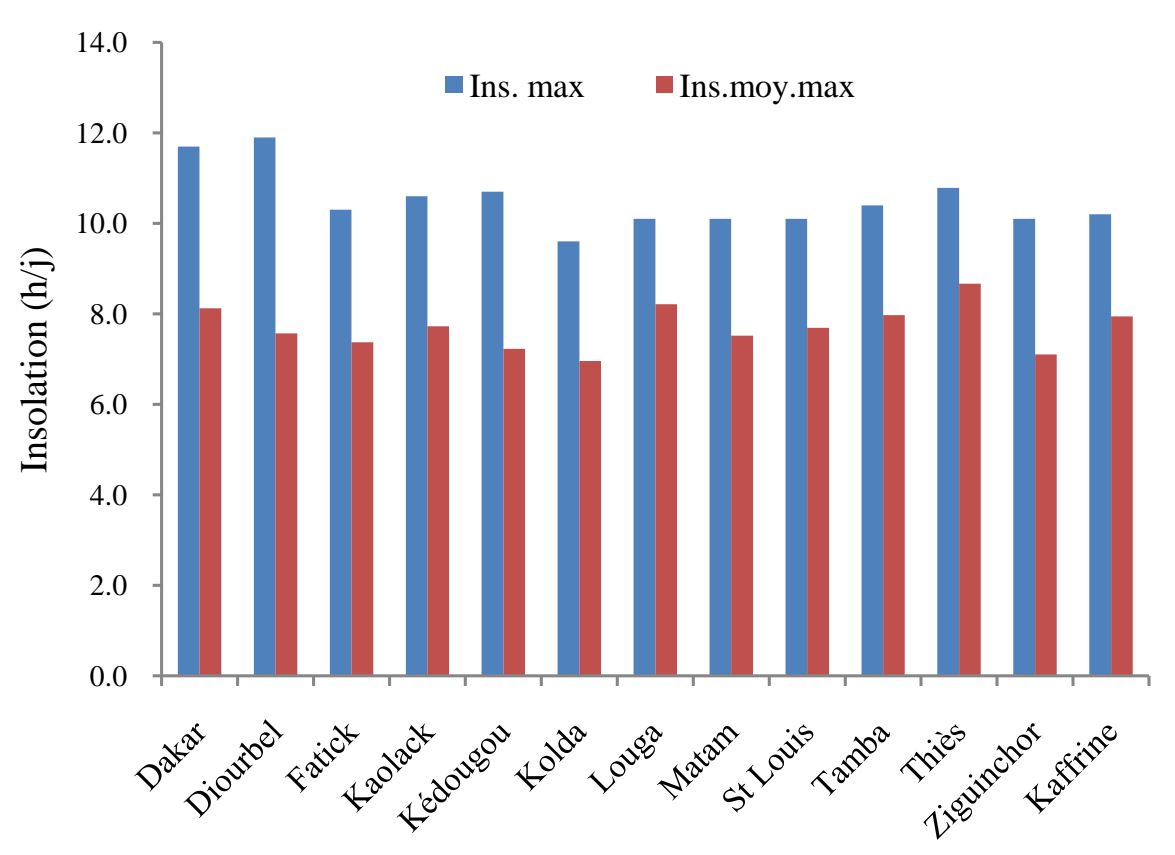

Figure 7. Graph of maximum and maximum mean insolation in Senegal [4]. Max = maximum; $\mathrm{m}=$ mean; $\min =$ minimum $;$ Teq $=$ equivalent temperature $;$ Tmax $=$ Maximum monthly average temperature; Tm.max = Average temperature 2007-2017; Tm.min $=$ Minimum monthly average temperature.

are observed between March, April and May for the regions except for the regions of Dakar, St Louis and Thies which observe their maximum values in October and November. Low temperatures occur in December, January and February. The duration of sunshine is often expressed in hours/year or hours/month or even hours/day and is scattered according to the region (Figure 7). Analysis of this figure shows maximum supplies between February and May, induced by clear skies, with maximum values ranging from $9.6 \mathrm{~h} / \mathrm{d}$ to $11.9 \mathrm{~h} / \mathrm{d}$. These values will decrease during the rainy season due to the cloud cover, which will keep the area under low radiation, then reducing the amount of sunshine. After this period, there is an increase between October and November, followed by a drop in December and January.

These temperature and insolation values are used to set the oven in the right condition. Since low temperatures do not adversely affect the behavior of the asphalt mixes, we are working with the maximum average values for the period 2007 to 2017. The temperature and the insolation are used as the temperature and duration of the drying process respectively. This is in the interest of simulating the behavior of the asphalt mix depending on the area. For this purpose, we subdivide the Senegalese territory into climatic zones based on Figure 6 and Figure 7 (Table 5).

\section{Thermal Sensitivity of Bitumen $50 / 70$}

The susceptibility of bitumen is the characteristic marking its ability to vary 
Table 5. Breakdown of Senegal's regions into climatic zones.

\begin{tabular}{cccc}
\hline Climatic zones & Regions & $\mathrm{T}^{\circ}$ max. & Insolation \\
\hline A & Diourbel-Matam-Kaffrine & $45^{\circ} \mathrm{C}$ & $12 \mathrm{~h}$ \\
$\mathrm{~B}$ & Ziguinchor-Tambacounda-Kolda-Fatick-Kaolack- & $43^{\circ} \mathrm{C}$ & $11 \mathrm{~h}$ \\
$\mathrm{C}$ & Kédougou & $40^{\circ} \mathrm{C}$ & $11 \mathrm{~h}$ \\
$\mathrm{D}$ & Thiès-Louga-St Louis & $33^{\circ} \mathrm{C}$ & $12 \mathrm{~h}$ \\
\hline
\end{tabular}

more or less in consistency for a given variation in temperature. In hot countries such as Senegal, where the behavior of bitumen during periods of high temperatures must be examined, it is undoubtedly the susceptibility to penetration that must be considered. In order to determine this susceptibility, the needle penetrability test is held at several temperatures. The Marshall performance according to climatic zones was also evaluated. Marshall test tubes made under the oven conditions of the zone (temperature and exposure) are crushed immediately on exit from the oven, both the maximum force and the creep are noted. Figures 8-10 present results of the 50/70 bitumen susceptibility study.

We clearly see that penetrability is a growing function of temperature, as the temperature rises, the bitumen loses consistency and becomes more fluid, which justifies its vulnerability to penetration. From a mechanical point of view, an increase in penetrability indicates a loss of strength and then a loss of stiffness of the asphalt. In reality, in high-temperature areas, this can lead to the appearance of instability, especially rutting.

We can see from the curve (Figure 10) that Marshall Stability is a negative function of temperature. When the temperature increases, the maximum breaking force decreases, which indicates a decrease in the strength of the bituminous material. Knowing that there is a relationship between the breaking force and the stiffness of the material, a positive correlation relationship, we can state with certainty that the modulus of rigidity of the $\mathrm{BB}$ is sensitive and decreases following a variation with increasing temperature. This remains contradictory with the constant modulus set at $1896 \mathrm{MPa}$ for a class 3 semi-grained bituminous concrete as given in the Ageroute catalogue in 2015 and used in Senegal's road projects. At the same time, we note an increase in creep if the temperature rises. This is justified by the fact that the material compresses more before breaking.

\section{Analytical Assessment}

\subsection{Sizing According to the AGEROUTE of Senegal Catalogue}

We dimension the pavement structure according to the parameters given in the catalogue's guide for the dimensioning of new pavement structures [5]. This involves setting up a pavement structure according to the catalogue values, most of which are approved and integrated into the dimensioning without any prior justification. This dimensioned structure can nevertheless provide stress and deformation values that comply with those admissible (Table 6). 


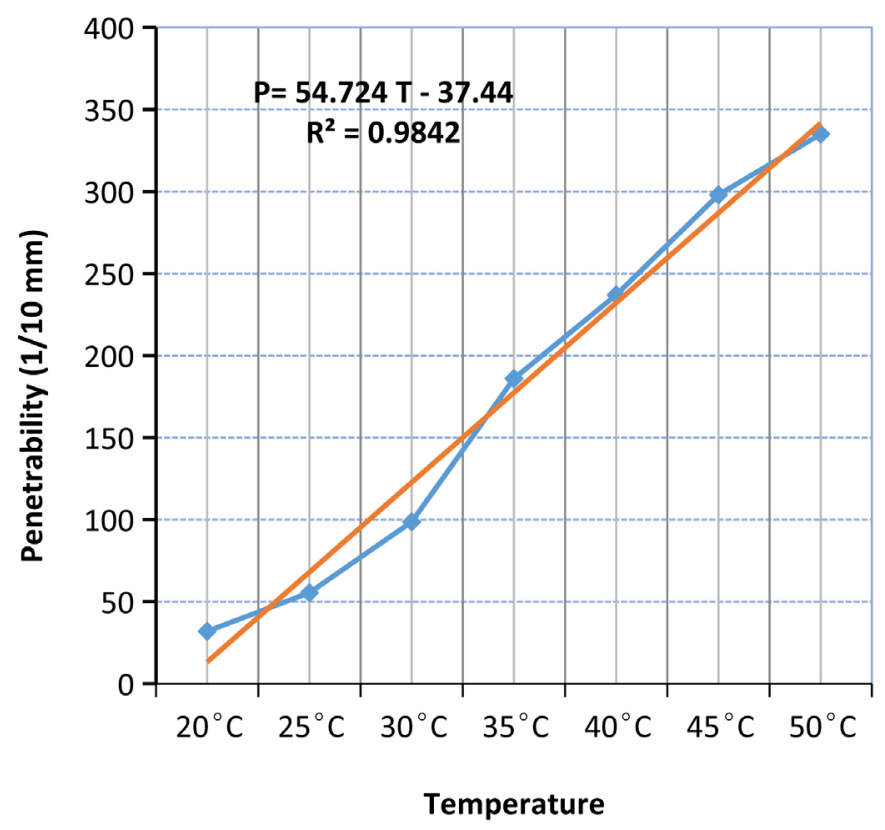

Figure 8. Penetrability curve depending on the temperature.

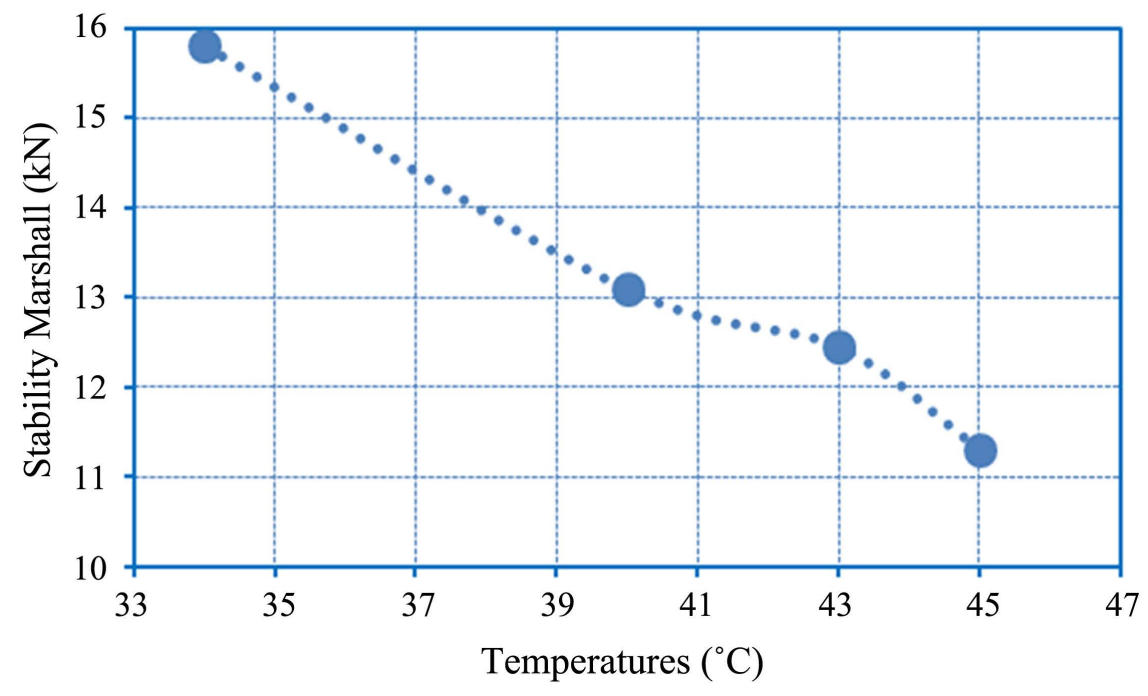

Figure 9. Marshall stability by maximum zone temperature.

Table 6. Dimensioning results according to fixed modules [5].

\begin{tabular}{|c|c|c|c|c|c|c|c|c|}
\hline \multirow{2}{*}{ Characteristics } & \multicolumn{8}{|c|}{ Layers } \\
\hline & \multicolumn{2}{|c|}{ BBSG3 } & \multicolumn{2}{|c|}{ GB4 } & \multicolumn{2}{|c|}{ Gla } & \multicolumn{2}{|c|}{ PF2 } \\
\hline Thicknesses & \multicolumn{2}{|c|}{5} & \multicolumn{2}{|c|}{8} & \multicolumn{2}{|c|}{29} & \multicolumn{2}{|c|}{ - } \\
\hline Parameter & cal. & adm. & cal. & adm. & cal. & adm. & cal. & adm. \\
\hline$\varepsilon_{t}(\mu \mathrm{def})$ & 14 & $<121$ & 54 & $<144$ & & & & \\
\hline$\sigma_{t}\left(10^{-3} \mathrm{MPa}\right)$ & \multicolumn{4}{|c|}{ - } & 260 & $<299$ & \multicolumn{2}{|c|}{ - } \\
\hline $\mathcal{E}_{z}(\mu \mathrm{def})$ & \multicolumn{4}{|c|}{ - } & \multicolumn{2}{|c|}{ - } & 368 & $<372$ \\
\hline
\end{tabular}

$\mathrm{adm}=$ eligible; $\mathrm{cal}=$ calculated . 


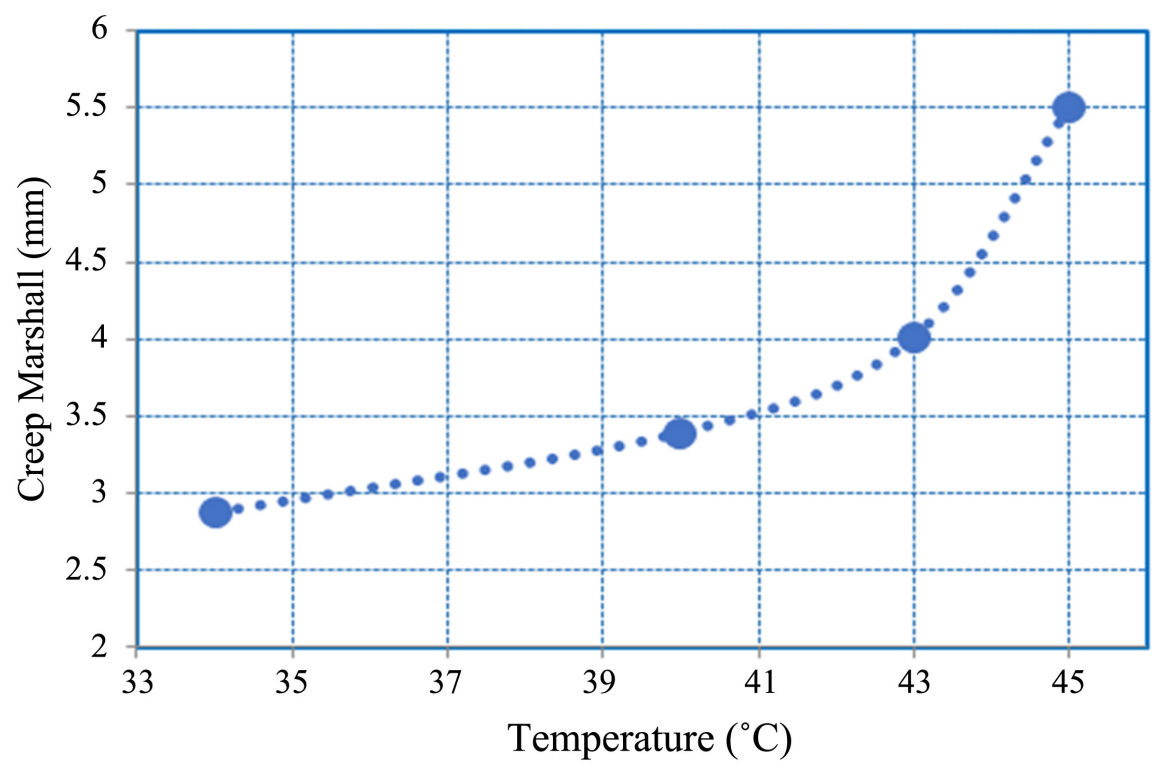

Figure 10. Marshall creep depending on the maximum zone temperature.

The results obtained from the data of the catalogue of Senegal allowed us to retain this structure: 5BBSG3/8GB4/29GLa/PF2 with stresses and deformations respecting the permissible limits. The tensile deformations found are relatively low in front of the admissible limit values. This could be avoided by reducing the thickness of the bearing and base layer. However, the values chosen correspond to the minimum thicknesses of the materials that constitute these layers. At the same time, the bonded interfaces lead to much higher stresses in the deepest layer.

Setting the value of the function modulus of $34^{\circ} \mathrm{C}$ as the equivalent temperature in the absence of a modulus test does not offer any possibility of determining the variation of this parameter related to the temperature. We conclude that according to Ageroute from Senegal, with E (BB) set at $\theta=34^{\circ} \mathrm{C}$ at $20 \mathrm{hz}$, the structure would suffer from the same thermal damage regardless of $\theta$ in the project area. This remains contradictory to the results shown above and not rational.

\subsection{Modeling According to the Default Parameters in Alize ${ }^{\circledR}$ LCPC}

Dimensioning catalogue for new pavements in Senegal specifies only one dimensioning temperature, which is the equivalent temperature of $34^{\circ} \mathrm{C}$ with a frequency of $20 \mathrm{~Hz}$. This being the case, in order to better adapt to our situation and to follow the effect of a temperature variation, we will use the default values in Alize. It will be a question of varying the ambient temperature, which is similar to the equivalent temperature, by zone and keeping the default frequency of $10 \mathrm{~Hz}$. We will start from the reference conditions $\left(34^{\circ} \mathrm{C}, 10 \mathrm{~Hz}\right)$ in order to set up a structure with stresses and deformations that meet the permissible limit conditions (Table 7). The temperature of the $\mathrm{BB}$ will then be adjusted according 
Table 7. Reference dimensioning according to Alize-LCPC $\left(34^{\circ} \mathrm{C}, 10 \mathrm{~Hz}\right)$.

\begin{tabular}{|c|c|c|c|c|c|c|c|c|}
\hline \multirow{2}{*}{ Characteristics } & \multicolumn{8}{|c|}{ Layers } \\
\hline & \multicolumn{2}{|c|}{ BBSG3 } & \multicolumn{2}{|c|}{ GB4 } & \multicolumn{2}{|c|}{ Gla } & \multicolumn{2}{|c|}{ PF2 } \\
\hline Thicknesses & \multicolumn{2}{|c|}{5} & \multicolumn{2}{|c|}{8} & \multicolumn{2}{|c|}{30} & \multicolumn{2}{|c|}{ - } \\
\hline Parametre & cal. & adm. & cal. & adm. & cal. & adm. & cal. & adm. \\
\hline$\varepsilon_{t}(\mu \mathrm{def})$ & 42 & $<121$ & 46 & $<144$ & & & \multirow{2}{*}{\multicolumn{2}{|c|}{ - }} \\
\hline$\sigma_{t}\left(10^{-3} \mathrm{MPa}\right)$ & & & & & 260 & $<299$ & & \\
\hline$\varepsilon_{z}(\mu \mathrm{def})$ & & & & & & & 370.7 & $<372$ \\
\hline
\end{tabular}

to the maximum monthly average temperature of the region under consideration. The parameters concerning the foundation and base layers as well as the platform and the layer thickness remain unchanged in order to better understand the sensitivity of the BB to temperature.

The results obtained from Alize LCPC default data allowed us to retain this structure: 5BBSG3/8GB4/30GLa/PF2 with stresses and deformations respecting the permissible limits. The modulus of the BBSG under these conditions is taken equal to $1180 \mathrm{MPa}$ at $34^{\circ}$ and $10 \mathrm{~Hz}$.

A variation in the temperature of the bearing layer according to the temperature of the zone makes it possible to follow the evolution of the deformations. The most important of which are observed at the base of the bearing layer and at the top of the platform shown in Figure 11 and Figure 12 respectively.

From Figure 12, we see that with the same parameters and dimensioned structure, the tensile deformation $\left(\varepsilon_{t, \text { cal }}\right)$ at the base of the surface layer increases if the project is carried out in other regions with actual temperatures exceeding $34^{\circ} \mathrm{C}$. This is due to the decrease in resistance of the material, which connotes the decrease in the stiffness of the bearing layer due to the effect of an increase in temperature. This clearly shows that stiffness and temperature are negatively correlated for bituminous concretes; this means BB is heat-susceptible. However, these deformation variations at the level of the BBSG3 remain within the admissible limit even if the project is carried out in the hottest zone of the country. However, they do not interfere in any way with the rupture of the structure from the top of the platform, where the stresses are more severe due to the bonded nature of the interfaces and are higher than those admissible.

If however the proposed structure is carried in the regions (Kaffrine, Diourbel, Tambacounda and Thiès), the deformations $\mathcal{E}_{Z \text {,cal }}$ exceed the acceptable value calculated at the reference $\left(34^{\circ} \mathrm{C}, 10 \mathrm{~Hz}\right)$ and in Dakar we always remain. within the acceptable limits as shown in Figure 12. This clearly corroborates the experiment that proves that an increasing variation of the dimensioning temperature for the same structure. This favors a decrease in the stiffness of the material considered $(\mathrm{BB})$ and accentuates the stresses and deformations in the material. These results prove that it is by far possible and rational to design a pavement structure. This generalized way based on the temperature of the cities (less hot) 


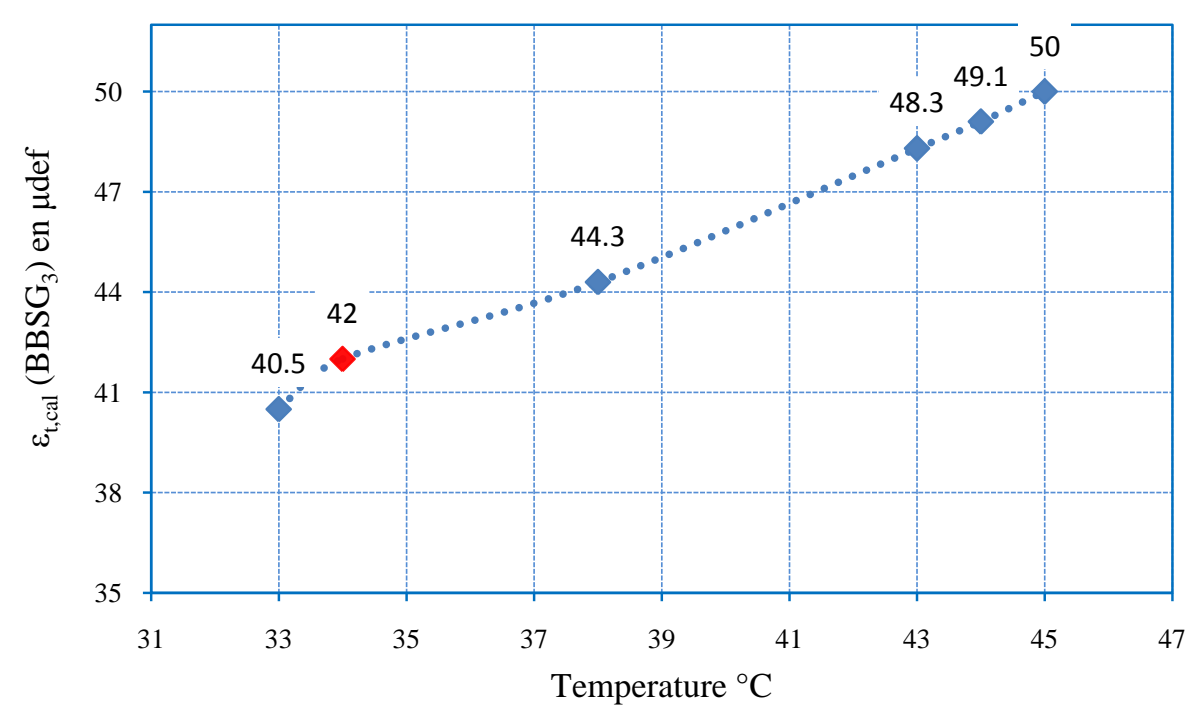

Figure 11. Tensile deformation at the base of the BBSG3 according to temperature.

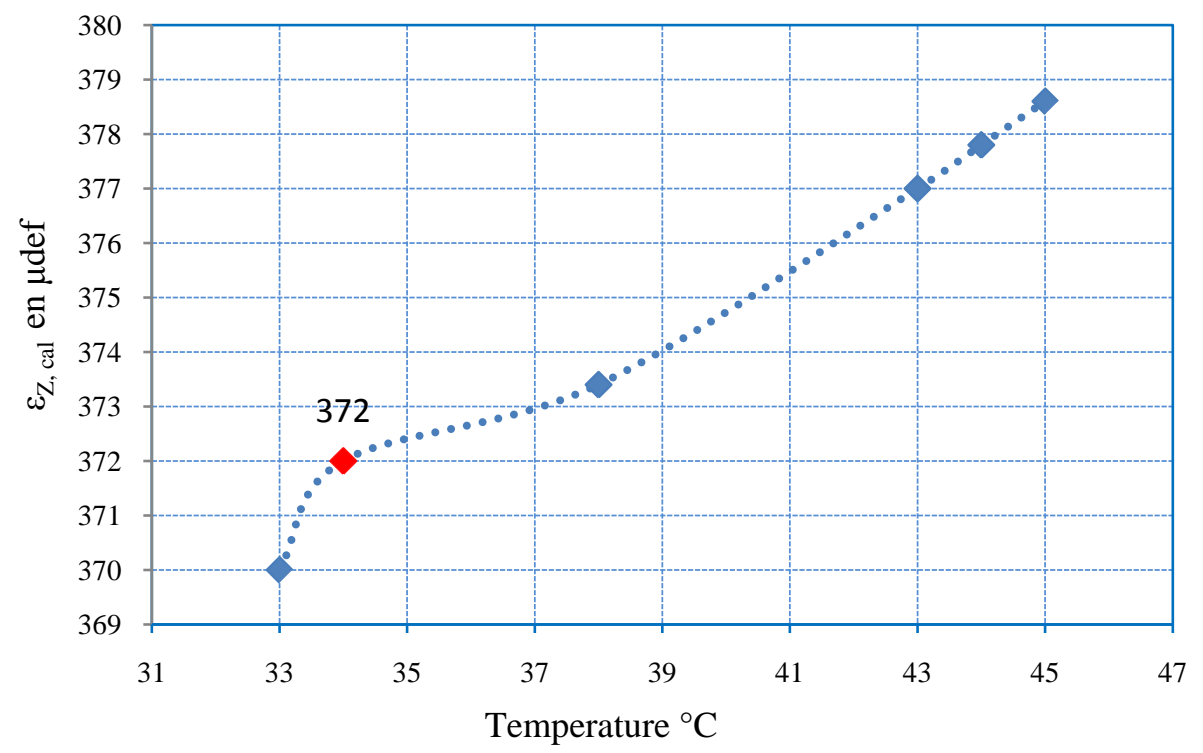

Figure 12. Evolution of the deformation at the top of the platform depending on the temperature of the zones.

and then a constant modulus in order to achieve good mechanical performances and to perpetuate the road heritage in the interior of the country.

\section{Current Situation}

The state of Senegal's roads shows instabilities characterized by thermal cracking, rutting, uprooting, potholes, bleeding and even too severe damage, among other things. The study of these causes is far from being covered by our research but we can nevertheless correlate these instabilities to the effects of the ambient temperature. We were able to take images that could illustrate these studies in these areas as shown in the table below (Table 8). 
Table 8. Road situations of some cities (June 2018).

\begin{tabular}{|c|c|c|c|}
\hline Cities & Tmax & Photos & Appreciations \\
\hline 3 & 33 & & $\begin{array}{l}\text { Good road } \\
\text { conditions }\end{array}$ \\
\hline $\begin{array}{l}\text { Thiès } \\
\text { (Thiénaba) }\end{array}$ & 38 & & Severe rutting \\
\hline $\begin{array}{l}\text { Tamba } \\
\text { (RN1) }\end{array}$ & 43 & & $\begin{array}{c}\text { Rutting and } \\
\text { potholes }\end{array}$ \\
\hline Diourbel & 44 & & $\begin{array}{l}\text { Rutting and } \\
\text { potholes, } \\
\text { stickiness } \\
\text { problem }\end{array}$ \\
\hline $\begin{array}{l}\text { Kaffrine } \\
\text { (RN1) }\end{array}$ & 45 & & $\begin{array}{l}\text { Severe rutting } \\
\text { and pullouts }\end{array}$ \\
\hline
\end{tabular}

Table 8 shows the road situation in different regions of Senegal. Apart from the Dakar region, where the average maximum temperature is lower than the dimensioning temperature. All other roads are submitted to potholes-type instabilities, but the most frequent remains rutting. Since the consistency as well as the stiffness of bituminous materials decreases with temperature, which suggests that these degradations are partly due to an increase in temperature. This decrease in the mechanical performance of these materials seems to be in agreement with the results found in the laboratory. From our experimentation, it is noted that the results of penetrability and Marshall creep increase significantly when the temperature is increased from $20^{\circ} \mathrm{C}$ to $50^{\circ} \mathrm{C}$ and $33^{\circ} \mathrm{C}$ to $45^{\circ} \mathrm{C}$ respectively. This growth may favour the rutting phenomena observed at Thiès (Thiénaba) 
and Kaffrine. On the other hand, the potholes observed at Tamba and Diourbel and the fatigue cracking observed in the Kaffrine area seem to be linked to a decrease in Marshall Stability according to the increasing of temperature. Furthermore, the simulation carried out on Alize-LCPC shows an increase in tensile deformation at the base of the bearing layer, which increases from $40.5 \mu$ déf to $50 \mu$ déf between the Dakar and Kaffrine regions, but also deformations at the top of the platform exceeding the permissible values. Visually we notice a rise of the bitumen on the road surface and this phenomenon commonly called bleeding under the effect of temperature and traffic, favours rutting. This is of concern to road professionals, in particular the Ageroute and the control offices, in terms of the quantification of bitumen in asphalt mixes and a good temperature control, which causes the rigidity of the material to drop and induces premature deterioration of the bearing layer. Better consideration of temperature as an input parameter could be taken into account to expect better mechanical performance in order to have quality and long life pavements. This would reduce the cost of maintenance and would be part of a dynamic of sustainability of the Senegalese road heritage.

\section{Conclusions}

As just shown, we conclude that the granules through physical and mechanical identification tests are of good quality to be used as input for the bearing layer of the project. In the same way, the bitumen delivered confirms the class but remains susceptible to temperature.

These results combined with a good choice of mix design curve allowed the formulation of an asphalt mix that, through the Marshall and Duriez test meets the requirements of the AIBD-MBOUR-THIES project.

Furthermore, the results show that asphalt mixes are thermally sensitive materials and their performance drops with increasing temperature variation. This fact was highlighted by the Marshall test, in which the material loses stability and creep increases as the temperature rises. In addition, a simulation on Alize that proves the temperature alone is sufficient to create disorders in the structure by exceeding the stresses to those permissible. This confirms the urgent need to calibrate it properly according to the project's location, to the detriment of the hypothesis of setting it at $34^{\circ} \mathrm{C}$, as recommended by Ageroute in an environment where climatic conditions vary from one environment to another. This proves that Ageroute's hypothesis of setting the temperature at $34^{\circ} \mathrm{C}$ with constant bearing layer E-moduli generalized in any project in the country is irrational. it is therefore important to use regional equivalent temperatures in order to deduce temperature damage. The knowledge of the equivalent regional temperature will make it possible to produce quality pavements with a long lifespan.

\section{Conflicts of Interest}

The authors declare no conflicts of interest regarding the publication of this paper. 


\section{References}

[1] Fall, M., Sawangsuriya, A., Benson, C.H., Edil, T.B. and Bosscher, P.J. (2007) On the Investigations of Resilient Modulus of Residual Tropical Gravel Lateritic Soils from Senegal (West Africa). Geotechnical and Geological Engineering, 26, Article No. 13. https://doi.org/10.1007/s10706-007-9144-5

[2] Dione, A. (2015) Estimation of the Reversible Modulus of Untreated Gravel and Finite Element Modelling of Flexible Pavements for Mechanistic-Empirical Design. Doctoral Thesis at ED2DS UFR SI, $184 \mathrm{p}$.

[3] Aidara, M.L.C. (2016) The Complex Modulus and Impact of Aggregate on the Prediction of the Dynamic Modulus of Asphalt Pavements. Application on Rationnel Dimensionings and Mechanistic-Empirical. Doctor of Philosophy Thesis at ED2DS UFR SI, $265 \mathrm{p}$.

[4] ANACIM (2007) Guide Technique.

[5] AGEROUTE (2015) Catalogue de structures de chaussées neuves et Guide de dimensionnement des chaussées au Sénégal, 214 p. 